\title{
Onset of foraging and lifespan of Africanized honey bees (Apis mellifera) infected with different levels of Nosema ceranae spores in Neotropical Mexico
}

\author{
Fernando A. Fleites-Ayil, José Javier G. Quezada-Euán, Luis A. Medina-Medina \\ Departamento de Apicultura, Campus de Ciencias Biológicas y Agropecuarias, Universidad Autónoma de Yucatán \\ Apdo, Postal 4-116, 97100, Merida, Yucatan, Mexico
}

Received 2 March 2018 - Revised 8 July 2018 - Accepted 6 September 2018

\begin{abstract}
Nosema ceranae is a microsporidium pathogen widely spread around the world. Negative effects on foraging behavior and longevity of EHB colonies have been associated with this pathogen as well as possible population losses, but its effects have not been studied in tropical adapted honey bees. We studied the interaction between this pathogen and Africanized honey bees (AHB) in the Yucatan peninsula of Mexico where $N$. ceranae has only been detected since 2008. Non-infected and artificially infected workers with two different spore concentrations were introduced in observation hives to evaluate the onset and duration of foraging and longevity. The results showed precocious foraging, a reduction of the duration of foraging and a decrease in the longevity of infected bees compared with non-infected ones. However, the results indicate that although negative effects can be caused by $N$. ceranae in AHB, these were of a moderate magnitude compared with similar reports on EHB in temperate areas. Further research is necessary to evaluate the long-term effect of $N$. ceranae on AHBs in relation to colony dynamics to better understand the absence of significant colony losses associated with this pathogen in tropical and subtropical Mexico.
\end{abstract}

\section{Nosema ceranae / foraging behavior / longevity / Nosemosis / Africanized bees}

\section{INTRODUCTION}

The microsporidium Nosema ceranae is one of the most widely distributed honey bee pathogens (Goulson et al. 2015), causing severe damage to colonies in temperate areas. $N$. ceranae has successfully infected the Western honey bee Apis mellifera since at least 1998 (Paxton et al. 2007; Higes et al. 2006). Infections of the digestive tract occur with a rapid division inside the ventricular cells causing degeneration of the epithelium (Higes et al. 2007). Infected workers suffer nutritional stress (Mayack and Naug 2009) which

Corresponding author: L. Medina-Medina, mmedina@correo.uady.mx

Manuscript editor: Peter Rosenkranz affects several aspects of individual life; among the most important is a reduction in the lifespan (Higes et al. 2007; Paxton et al. 2007; Goblirsch et al. 2013). It also affects the orientation and homing skills of workers (Kralj and Fuchs, 2010; Wolf et al. 2014) and induces their early foraging (Goblirsch et al. 2013).

The effects of $N$. ceranae on honey bees from tropical regions have been poorly documented, mostly limited to reports of the presence of this microsporidium in different countries (GuzmánNovoa et al. 2011; Teixeira et al. 2013; Santos et al. 2014). In tropical and subtropical Mexico, Africanized honeybee (AHB) colonies are predominant (Domínguez-Ayala et al. 2016). In Brazil, laboratory studies have confirmed a reduced survival of Africanized honey bee workers infected with $N$. ceranae under controlled conditions (Gregorc et al. 2016). However, there is no 
evidence of the effects of $N$. ceranae on whole colonies and under field conditions.

The Yucatan Peninsula is Mexico's leading beekeeping region with an estimated number of managed AHBs around 375,000 (Quezada-Euán 2007; SIAP-SAGARPA, 2016). The $N$. ceranae species in Mexico seems to be present since at least 1995 (Guerrero-Molina et al. 2016). In the state of Yucatan, the frequency of managed honey bee colonies positive to Nosema sp. infection significantly increased from $7.2-13.3 \%$ in the early 1990 s, to $82 \%$ of prevalence, out of 165 colonies sampled from 13 different localities throughout the state in 2006 (García-Millán and QuezadaEuán 1993; Martínez-Puc et al. 2011).

There is evidence of detrimental effects of $N$. ceranae on the onset of foraging and longevity of EHBs (Goblirsch et al. 2013; Natsopoulou et al. 2016). These traits are important components of colony fitness which could affect survival (Higes et al. 2008; Higes et al. 2009; Botías et al. 2013). Nevertheless, it is yet unknown if compared to the situation in temperate areas, the interaction between $N$. ceranae and AHBs in the Neotropics could be of a similar detrimental magnitude. In this study, we performed an evaluation of the effects of $N$. ceranae on the onset of foraging, duration of foraging, and longevity in AHB workers in whole colonies under field conditions.

\section{MATERIALS AND METHODS}

\subsection{Study site, colony racial origin, and Nosema species}

The study was carried out in the Department of Tropical Apiculture of the Faculty of Veterinary Medicine, of Universidad Autónoma de Yucatán at Xmatkuil, Mexico, between March 2014 and February 2015. Because $N$. ceranae and $N$. apis are both found in the study region, the species of Nosema infecting colonies was confirmed from worker samples (60 individuals) collected from each of 21 colonies of an experimental apiary. The samples were analyzed by conventional PCR based on the alignment of the preserved sequence of the small subunit $16 \mathrm{~S}$ rRNA gene (Chen et al. 2008).
Identification of $N$. ceranae and $N$. apis was based on the length of the amplified segment, 250 or 401 bp, respectively (Chen et al. 2008). The racial origin of the experimental colonies was determined with the standard molecular procedures where primers E2 and H2 were used for DNA amplification extracted from the thoracic muscles (one worker bee per colony) in order to identify the African mitotype (Garnery et al. 1993). The Fast Africanized Bees Identification System (FABIS) based on morphometrics was also used to confirm the origin of the colonies (Quezada-Euán and Medina 1998; Nielsen et al. 1999).

\subsection{Establishment of observation hives}

The molecular results identified ten colonies infected with $N$. ceranae only. Seven of these colonies were treated with Fumagilin-B® in order to reduce parasite loads using $1.2 \mathrm{~g}$ of the product dissolved in 11 of sugar syrup (2:1 sugar:water). Colonies were treated every week during 1 month (four applications) and at the end of this period, the reduction of spore loads was confirmed showing an efficacy of $98.4 \%$, similar to data reported elsewhere (Williams et al. 2011). Three AHB queen right colonies previously treated with Fumagilin-B® were placed in separate observation hives with two standard Langstroth frames 45 days before the beginning of the experiments. Workers in these hives were allowed to forage freely by connecting a plastic tube from the lower part of the observation hive to the exterior (Scheiner et al. 2013). Observation hives were separated from each other by two meters, and the external entrances of each observation hive were painted with different colored patterns to reduce drifting. The top frame of each observation colony contained a mixture of open and capped cells with honey and pollen, and the bottom frame contained brood in different stages; all observation hives had similar amounts of worker bees, pollen, and nectar-honey. Additionally, the observation hives were fed with sugar syrup twice a week and adapted with queen bee excluder mesh at the entrance to avoid swarming. 


\subsection{Infection procedure}

From four colonies treated with Fumagilin-B®, we took frames with worker capped brood cells and maintained them in an incubation chamber at $34{ }^{\circ} \mathrm{C}$ and $70 \% \mathrm{RH}$ for $24 \mathrm{~h}$ to obtain young bees non-infected with $N$. ceranae.

To infect recently emerged workers, fresh $N$. ceranae inocula were prepared using forager bees collected at the hive entrances from the three remaining colonies previously identified as infected with the parasite but that were not treated with Fumagilin-B®. The ventricles of 200 workers were dissected and crushed in distilled purified water to produce the inoculum (Fries et al. 2013). The number of spores was counted with the help of a hemocytometer grid. The amount of spores per microliter was determined, to finally calculate the volume of concentrate that was required for each dose for infection (Human et al. 2013; Fries et al. 2013). Additionally, we confirmed that only $N$. ceranae was present in the concentrate by means of PCR (Chen et al. 2008).

Newly emerged AHB workers from the four different colonies were mixed and randomly assigned to each treatment, to avoid possible colony effects. The treatments consisted on individuals fed with $10 \mu \mathrm{l}$ sugar syrup (50\% w/v) containing 10,000 spores (Treatment $1=\mathrm{T} 1$ ) or 50,000 spores (Treatment $2=\mathrm{T} 2$ ) of $N$. ceranae . As a control, cohorts of workers were fed $10 \mu \mathrm{l}$ of sugar syrup only (Treatment $0=\mathrm{T} 0$ ). Three cohorts of 180 workers for each treatment were marked with numbered colored plastic tags to identify them individually and 1620 workers in total were marked for this study. After inoculation and marking, the different groups of bees were kept separately in wooden cages $(10 \times 10 \times 8 \mathrm{~cm})$ and maintained during $24 \mathrm{~h}$ in an incubation chamber $\left(36^{\circ} \mathrm{C}\right.$ and $70 \%$ HR) before being introduced to the three observation hives. This period allowed discarding bees affected by handling (Scheiner et al. 2013; Fries et al. 2013).

In total, 1030 worker bees were introduced into the observation hives for the three treatments: 309 workers in T1, 300 workers in T2, and 421 workers in $\mathrm{T} 0$.

To confirm the rate of infestation, 40 workers of each treatment were maintained separately in wooden cages in an incubation chamber $\left(36^{\circ} \mathrm{C}\right.$ and $70 \% \mathrm{HR}$ ) during a period of 12 days, after which all bees were sacrificed to determine the degree of infection of $N$. ceranae by counting the spores using a hemocytometer (Cantwell 1970; Fries et al. 2013).

\subsection{Assessment of the onset and duration of foraging behavior and longevity}

A scan observation was used to record the onset of foraging behavior in all marked bees (infected and non-infected) introduced in the three observation hives (Kolmes 1984); this scan method consisted of carefully spotting and observing marked bees in both sides of each comb of the three experimental colonies. The behavior of the marked workers was recorded every day between 08:00 and 11:00 $\mathrm{h}$ in the morning with three observations of $20 \mathrm{~min}$ (1 hour per colony) in each observation hive in a random order. The onset of foraging behavior in a marked worker was considered as the first time the worker returned to the hive with pellets of pollen in the corbicula or when it transferred nectar to receiver bees (Hart and Ratnieks 2001), or when it was observed performing waggle or circle dances to recruit nestmates. These are behaviors typically related to foraging activity (Seeley 1995). The duration of foraging activity (days that the workers spend as foragers) was recorded as the time at which marked bees started foraging activities until they were last seen in the hive.

To evaluate longevity, the presence of each marked bee was registered daily through three additional observations of $20 \mathrm{~min}$ ( $1 \mathrm{~h}$ per colony) in each hive. These observations were carried out at the end of the day (between 17:00 to 20:00 $\mathrm{h}$ in the afternoon), when most field bees were inside the hives. Longevity was considered as the number of days elapsed between the introduction of each bee to the observation hive until the day they were last spotted (Rueppell et al. 2007).

\subsection{Data analysis}

We compared the effect of infection on the onset and duration of foraging behavior using a generalized linear mixed model (GLMM) with R 
package "glmerMod." The treatments were used as fixed factors and observation hive as random factor. The longevity of the workers from noninfected and both infected treatments was evaluated using a Cox proportional hazard model (McMahon et al. 2016) with the $\mathrm{R}$ packages "coxme" (Therneau et al. 2003) and "coxph" (Therneau and Lumley 2015). We stablished the observation hive as a random factor.

\section{RESULTS}

$N$. ceranae spore load recorded in worker cohorts maintained under laboratory conditions confirmed the infection in the bees treated with two different spore concentration. At day 12 post infection, workers infected with 10,000 spores had an average of $532,400 \pm 107,000$ spores per bee while workers infected with 50,000 spores had an average of 1,312,600 $\pm 243,600$ spores per bee. We did not detect the presence of spores in workers from the control group (T0).

The onset of foraging was registered during a period of 50 days in 1030 marked workers, of which 421 belonged to the non-infected treatment ( $\mathrm{T} 0=$ non-infected workers), 309 belonged to $\mathrm{T} 1$ (workers infected with 10,000 spores), and 300 bees belonged to T2 (workers infected with 50,000 spores).

The results showed statistical differences between the two infected treatments compared with non-infected treatment (for T1-T0, GLMM Poisson error distribution $Z_{31030}=-23.36, p=$ 0.001 and for T2-T0, GLMM Poisson error distribution $\left.Z_{31030}=-23.92, p=0.001\right)$, showing that infected workers (T1 and T2) started to forage prematurely compared to non-infected ones (T0). On the other hand, we did not find differences between both infected treatments (T1-T2, GLMM Poisson error distribution $Z_{31030}=-0.802, p=$ $0.7)$. Indeed, AHB workers infected with 10,000 spores started foraging at $14.9 \pm 1.91(n=309)$ days of age while workers infected with 50,000 spores started this activity at $14.7 \pm 2.07(n=300)$ days of age. In comparison, non-infected AHB workers started foraging until day $22.7 \pm 2.82$ $(n=421)$ (Figure 1). These results indicate that AHB workers infected with $N$. ceranae began their foraging activities precociously and at

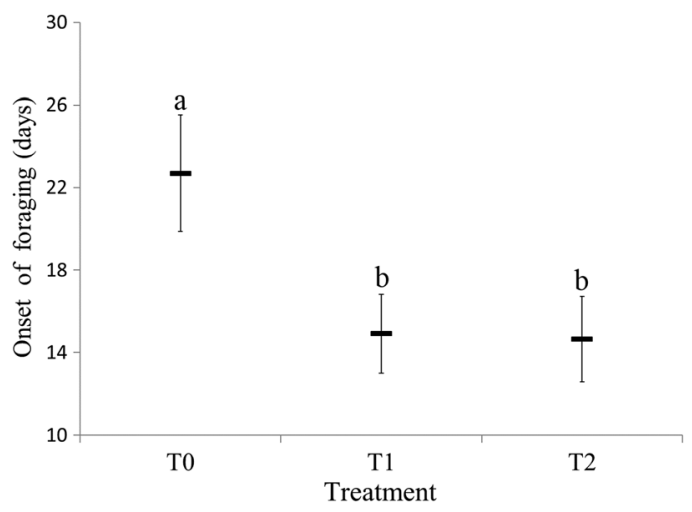

Fig. 1 The onset of foraging behavior (days) for the three treatments: T0 $=$ non-infected workers, T1 = workers infected with 10,000 spores, and T2 = workers infected with 50,000 spores. Dots and error bars represent the mean and standard deviation. Different letters indicate significant differences among treatments $(p<0.001)$.

similar ages under tropical conditions regardless of the number of spores inoculated.

Significant differences were also observed for the duration of foraging activity between bees of both $N$. ceranae infected treatments and noinfected treatment (for T1-T0, GLMM Poisson error distribution $Z_{3} 1026=-7.210, p=0.001$ and for T2-T0, GLMM Poisson error distribution $\left.Z_{31026}=-6.01, p=0.001\right)$. In contrast, infected treatments were not different from each other (T1T2, GLMM Poisson error distribution $Z_{31026}=$ $1.175, p=0.47$ ). AHB workers infected with the two levels of spores exhibited shorter duration of foraging activity $(\mathrm{T} 1=7.7 \pm 6.01$ days; $n=308$ and T2 $=8.3 \pm 6.06$ days, $n=297$ ), compared with non-infected workers $(9.59 \pm 6.42$ days, $n=421$ ) (Figure 2). The difference between both infected treatments and non-infected workers was 1 to 2 days on average (Figure 2).

For longevity, we found statistical differences among infected and non-infected bees $\left(X^{2}{ }_{3}\right.$, $1470=449.28, p=0.001$, Cox proportional hazard). AHB workers infected with $N$. ceranae (T1 and T2) had a reduced longevity compared to non-infected workers, but were not different from each other. AHB workers from T1 survived on average $21.6 \pm 6.6$ days $(n=483)$, bees from T2 did so for $21.3 \pm 6.8$ days $(n=484)$ and the 


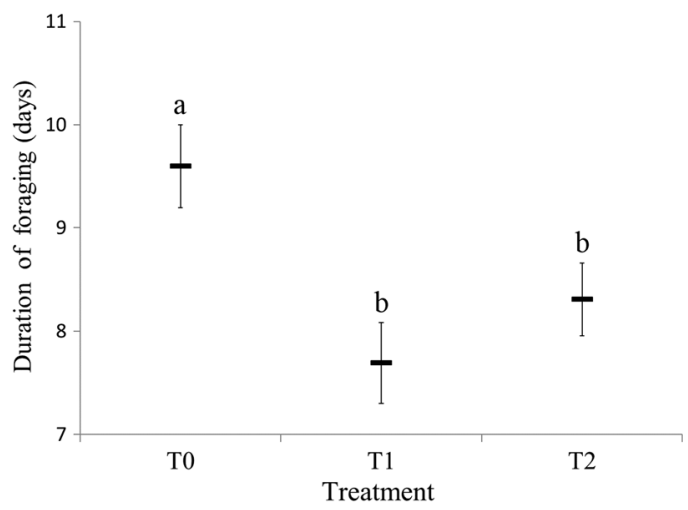

Fig. 2 The duration of foraging behavior (days) for the three treatments: T0 $=$ non-infected workers, $\mathrm{T} 1=$ workers infected with 10,000 spores, and T2 = workers infected with 50,000 spores. Dots and error bars represent the mean and standard error. Different letters indicate significant differences among treatments $(p<0.001)$.

non-infected bees survived $29.5 \pm 8.4$ days $(n=$ 503) (Figure 3).

For any of the former comparisons, we did not find significant statistical differences due to random effects (observation hive) $(\mathrm{SD}=0.3141$ Variance $=0.0986$ ).

\section{DISCUSSION}

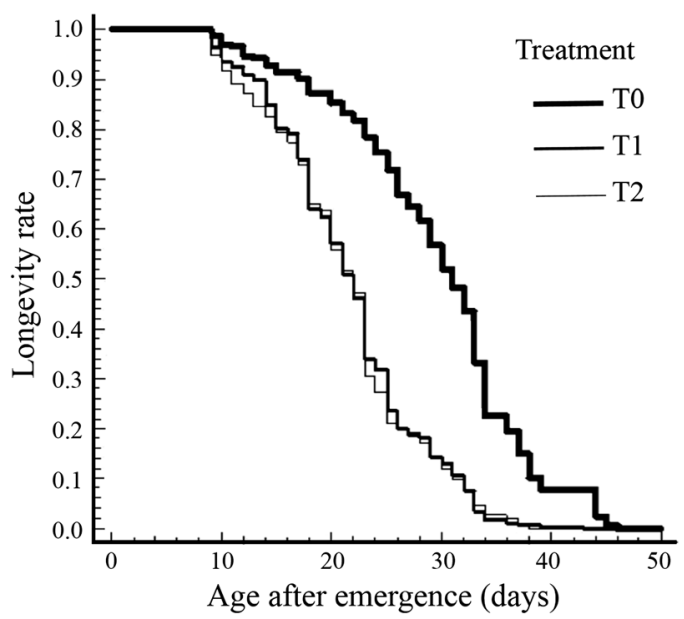

Fig. 3 Longevity rate curves of AHB workers for the three treatments: $\mathrm{T} 0=$ non-infected workers, $\mathrm{T} 1=$ workers infected with 10,000 spores, and $\mathrm{T} 2=$ workers infected with 50,000 spores.
In this study, we evaluated the effects of $N$. ceranae on the onset and duration of foraging activity and longevity in AHBs under tropical conditions. A negative effect of $N$. ceranae infection was found on both foraging activity and longevity. Workers infected with two levels of spores started foraging precociously and the duration of foraging was reduced compared with noninfected bees. In addition, longevity was diminished in both infected treatments compared with non-infected workers.

\subsection{Onset and duration of foraging in $N$. ceranae infected AHBs}

We found that AHB workers infected with $N$. ceranae under tropical conditions, experienced similar behavioral changes in foraging activity to those of EHBs in temperate regions (Goblirsch et al. 2013; Natsopoulou et al. 2016). Our AHBs infected with two different concentrations of $N$. ceranae spores $(10,000$ and 50,000$)$ started to forage on average 8 days earlier than non-infected bees. In EHB workers infected with $N$. apis, foraging started on average 10 days earlier (onset at 17.4 days old) than non-infected workers (Woyciechowski and Moron 2009). A negative influence of $N$. ceranae on the onset of foraging behavior in EHBs infected with 10,000 spores per bee was found by Goblirsch et al. (2013) under field conditions. They found that significantly more infected workers engaged in foraging at younger ages compared with noninfected workers (Goblirsch et al. 2013). On the other hand, Natsopoulou et al. (2016) also found that EHBs infected with $N$. ceranae had a tendency to start foraging earlier than control bees, but no statistical differences was observed between both groups.

Thus, we found that $N$. ceranae induced a similar precocious start of foraging in AHBs with a similar number of days (8 days on average) compared with EHBs.

It seems that AHB workers infected with $N$. ceranae transit from nest duties to foraging activities with evidence of an accelerated behavioral maturation similar to that found in EHBs (Holt et al. 2013; Lecocq et al. 2016). In other studies, precocious foraging in Nosema infected 
bees has been attributed to the destruction of the midgut tissue (Higes et al. 2007), which causes starvation, and a decrease in the levels of vitellogenin (Goblirsch et al. 2013), affecting age polyethism and inducing precocious foraging and premature senescence (Antúnez et al. 2009; Holt et al. 2013; Goblirsch et al. 2013).

We also found that $N$. ceranae infected AHBs foraged 1 to 2 days less than non-infected bees. Despite these results, apparently do not indicate big differences in the duration of this activity, the reduction of the duration of foraging could affect whole colony traits such as honey yield. Fries et al. (1984) reported that Nosemosis caused by $N$. apis has negative influences on honey yield due to the reduced lifespan of infected workers.

In addition, Naug (2014) found that EHB worker bees infected with $N$. ceranae perform longer foraging trips, spending less time in the nest between foraging trips but return with less amount of sucrose per trip that results in a less efficiency of energetic gain that probably explain the reduction of honey yield.

Recently, a negative relationship between honey production and the numbers of workers infected with $N$. ceranae was observed in AHBs from the Yucatan in Mexico (Martin and Medina unpubl. data). Our findings on the reduction of foraging in infected workers could be related to colony dynamics that need to be evaluated in the future.

\subsection{Worker longevity in $N$. ceranae infected AHBs}

N. ceranae infection reduced AHB worker longevity 8 days in average compared to noninfected bees under field conditions.

A similar negative effect of $N$. ceranae on worker longevity was found in EHBs under laboratory conditions, resulting in a reduction of lifespan ranging between 8 and 14 days (Higes et al. 2007; Paxton et al. 2007; Dussaubat et al. 2013). Our results (8 days of longevity reduction) are in general similar to those registered by Goblirsch et al. (2013) on EHB workers at similar levels of $N$. ceranae infection (10,000 spores per bee), resulting in a 9-day reduced lifespan compared with non-infected bees under field conditions. These authors assumed that the longevity reduction in infected bees could affect colony development (Goblirsch et al. 2013). Our results suggest that a similar reduction in lifespan occurs in AHBs infected with $N$. ceranae in the field. Similarly, EHB workers infected with $N$. apis also lived significantly less under both laboratory and field conditions compared with non-infected workers (Woyciechowski and Moron, 2009).

In summary, our results showed that AHB workers are susceptible to $N$. ceranae when infected artificially with this microsporidium which results in diminished in foraging activity and longevity under field conditions, as has been observed in EHBs. Nevertheless, massive colony losses due to $N$. ceranae in Neotropical regions seems rare (Vandame and Palacios 2010). This indicates the need of further research to evaluate the effects of this parasite in managed colonies as well as in wild swarms considering the effect of seasonality and other aspects of AHBs colony dynamics in Neotropical regions.

\section{ACKNOWLEDGEMENTS}

We thank Dr. Robert Paxton and PhD candidate Alice Séguret for constructive discussions and revision of the manuscript. We also thank Dr. Fernando Puerto Manzano for assistance in the molecular evaluations and Manuel Vazquez and Omar Sosa for assistance in laboratory and field observations.

\section{AUTHORS' CONTRIBUTIONS}

All authors have contributed equally to the work.

\section{COMPLIANCE WITH ETHICAL STANDARDS}

Conflict of interest The authors declare that they have no conflict of interest.

Début de butinage et durée de vie des abeilles africanisées (Apis mellifera) infectées par différents niveaux de spores de Nosema ceranae dans le Mexique néotropical 
Nosema ceranae / Comportement de butinage / longévité / nosémose / Abeilles africanisées

Der Beginn des Sammelverhaltens und die Lebenserwartung von Afrikanisierten Honigbienen (Apis mellifera), die im neotropischen Mexiko mit unterschiedlichen Dosierungen von Nosema ceranae Spores infiziert wurden

Nosema ceranae / Sammelverhalten / Lebenserwartung / Nosemosis / Afrikanisierte Bienen

\section{REFERENCES}

Antúnez, K., Martín-Hernández, R., Prieto, L., Meana, A., Zunino, P., Higes, M. (2009) Immune suppression in the honey bee (Apis mellifera) following infection by Nosema ceranae (Microsporidia). Environ. Microbiol. 11 (9), 2284-2290

Botías, C., Martín-Hernández, R., Barrios, L., Meana, A., Higes, M. (2013) Nosema spp. infection and its negative effects on honey bees (Apis mellifera iberiensis) at the colony level. Vet. Res. 44, 25

Cantwell, G.E. (1970) Standard methods for counting nosema spores. American Bee Journal 110 (6), 222223

Chen, Y., Evans, J.D., Smith, I.B., Pettis, J.S. (2008) Nosema ceranae is a long-present and wide-spread microsporidian infection of the European honey bee (Apis mellifera) in the United States. J. Invertebr. Pathol. 97, 186-188

Domínguez-Ayala, R., Moo-Valle, H., May-Itzá, W. de J., Medina-Peralta, S., Quezada-Euán, J. J. G. (2016) Stock composition of northern neotropical honey bees: mitotype and morphotype diversity in Mexico (Hymenoptera: Apidae). Apidologie 47, 642-652

Dussaubat, C., Maisonnasse, A., Crauser, D., Beslay, D., Costagliola, G., Soubeyrand, S., Kretzchmar, A., Le Conte, Y. (2013) Flight behavior and pheromone changes associated to Nosema ceranae infection of honeybee workers (Apis mellifera) in field conditions. J Invertebr Pathol. 113 :42-51

Fries, I., Ekbohm, G., Villumstad, E. (1984) Nosema apis, sampling techniques and honey yield. J. Apic. Res. 23 (2), 102-105

Fries, I., Chauzat, M.P., Chen, Y.P., Doublet, V., Genersch, E., et al. (2013) Standard methods for Nosema research. J. Apic. Res. 52 (1), 1-28

García-Millán, M., Quezada-Euán, J.J. (1993) Distribución de la Nosemosis en apiarios comerciales del estado de Yucatán. Apicultura Moderna 5, 22-24

Garnery, L., Solignac, M., Celebrano, G., Cornuet, J.M., (1993) A simple test using restricted PCR-amplified mitochondrial DNA to study the genetic structure of Apis mellifera L. Experientia 49, 1016-1020
Goblirsch, M., Huang, Z.Y., Spivak, M. (2013) Physiological and behavioral changes in honey bees (Apis mellifera ) induced by Nosema ceranae infection. Plos One. 8 (3), 1-8

Goulson, D., Nicholls, E., Botías, C., Rotheray, E. (2015) Bee declines driven by combined stress from parasites, pesticides, and lack of flowers. Science. 347, 1-7

Gregorc, A., Silva-Zacarin, E., Malfitano, S., Kramberger, D., Teixeira, E., Malaspina, O. (2016) Effects of Nosema ceranae and thiametoxam in Apis nellifera: A comparative study in Africanized and Carniolan Honey bees. Chemosphere. 147, 328-336

Guerrero-Molina, C., Correa-Benítez, A., Hamiduzzaman, M.M., Guzman-Novoa, E. (2016) Nosema ceranae is an old resident of honey bee (Apis mellifera) colonies in Mexico, causing infection levels of one million spores per bee or higher during summer and fall. J. Invertebr. Pathol. 141, 38-40

Guzmán-Novoa, E., Hamiduzzaman, M.M., Arechavaleta, M.E., Koleoglu, G. (2011) Nosema ceranae has parasited Africanized honey bees in Mexico since at least 2004. J. Apicul. Res. 50 (2), 167-169

Hart, A.G., Ratnieks, F.L.W. (2001) Why do honey-bee (Apis mellifera) foragers transfer nectar to several receivers? Information improvement through multiple sampling in a biological system. Behav. Ecol. Sociobiol. 49, 244-250

Higes, M., Martín-Hernández, R., Meana, A. (2006) Nosema ceranae, a new microsporidian parasite in honeybees in Europe. J. Invertebr. Pathol. 92, 93-95

Higes, M., García-Palencia, P., Martín-Hernández, R., Meana, A. (2007) Experimental infection of Apis mellifera honeybees with Nosema ceranae (Microsporidia). J. Invertebr. Pathol. 94, 211-217

Higes, M., Martín-Hernández, R., Botías, C., Garrido-Bailón, E., González-Porto, A.V. et al. (2008) How natural infection by Nosema ceranae causes honeybee colony collapse. Environ. Microbiol. 10 (10), 2659-2669

Higes, M., Martín-Hernández, R., Garrido-Bailón, E., González-Porto, A.V., García-Palencia, P., Meana, A., Del Nozal, M.J., Mayo, R., Bernal, J.L. (2009) Honeybee colony collapse due to Nosema ceranae in professional apiaries. Environ. Microbiol. Rep. 1, 110-113

Holt, H.L., Aronstein, K.A., Grozinger, C.M. (2013) Chronic parasitization by Nosema microsporidia causes global expression changes in core nutritional, metabolic and behavioral pathways in honey bee workers (Apis mellifera ). BMC Genom. 14, 1-16

Human, H., Brodschneider, R., Dietemann, V., Dively, G., Ellis, J. et al. (2013) Miscellaneous standard methods for Apis mellifera research. J. Apicul. Res. 52 (4), 1-56

Kolmes, S.A. (1984) A quantitative comparison of behavior methodologies for studies of worker honeybees. J. Apicul. Res. 23 (4): 189-198

Kralj, J., Fuchs, S. (2010) Nosema spp. influences flight behavior of infected honey bee (Apis mellifera) foragers. Apidologie 41 : 21-28

Lecocq, A., Jensen, A., Kryger. P., Nieh, J. (2016) Parasite infection accelerates age polyethism in Young honey 
bees. Sci. Rep., DOI: https://doi.org/10.1038 /srep22042

Mayack, C.; Naug, D. (2009) Energetic stress in the honeybee Apis mellifera from Nosema ceranae infection. J. Invertebr. Pathol. 100, 185-88

McMahon, D.P., Natsopoulou, M.E., Doublet, V., Fürst, M., Weging, S., Brown, M.J.F., Gogol-Döring, A., Paxton, R.J. (2016) Elevated virulence of an emerging viral genotype as a driver of honeybee loss. Proc. R. Soc. B 283, 20160811

Martínez-Puc, J.F., Medina-Medina, L.A., Catzin-Ventura, G. (2011) Frecuencia de Varroa destructor, Nosema apis y Acarapis woodi en colonias manejadas y enjambres silvestres de abejas (Apis mellifera) en Mérida, Yucatán, México. Rev. Mex. Cien. Pecu. 2 (1), 25-38

Natsopoulou, M.E., McMahon, D.P., Paxton, R.J. (2016) Parasites modulate within-colony activity and accelerate the temporal polyethism schedule of a social insect, the honey bee. Behav Ecol Sociobiol.70 (7), 10191031

Naug, D. (2014) Infected honeybee foragers incur a higher loss in efficiency than in the rate of energetic gain. Biol. Lett. 10, 20140731

Nielsen D.I., Ebert, P.R., Hunt, G.R., Guzmán-Novoa, E., Kinnee, S.A., Page, R.E. (1999) Identification of Africanized honey bees (Hymenoptera: Apidae) incorporating morphometrics and an improved polymerase chain reaction mitotyping procedure. A. Entom. Soc. Ame. 92 (2), 167-174

Paxton, R., Klee, J., Korpela, S., Fries, I. (2007) Nosema ceranae has infected Apis mellifera in Europe since at least 1998 and may be more virulent than Nosema apis . Apidologie. 38 (6), 558-565

Quezada-Euán, J.J.G. (2007) A retrospective history of the expansion of Africanized honey bees in Mexico. J. Apic. Res. and Bee World 46, 295-300

Quezada-Euán J.J.G., Medina L.M. (1998) Hybridisation between European and Africanized honeybees (Apis mellifera L.) in tropical Yucatan, México. I. Morphometric changes in feral and managed colonies. Apidologie 29, 555-568

Rueppell, O., Bachelier, C., Fondrk, M.K., Page, R.E. (2007) Regulation of life history determines lifespan of worker honey bees (Apis mellifera L.). Exp. Gerontol. 42, 1020-1032

Santos, L.G.; Alves, M.L., Message, D., Pinto, F.A., Silva, M.V., Teixeira, E.W. (2014) Honey bee health in apiaries in the Vale do Paraíba, São Paulo State, Southeastern Brazil. Sociobiology 6 (13), 307-312

Scheiner, R.; Abramson, C.I.; Brodschneider, R., Crailsheim, K., Farina, W. et al. (2013) Standard methods for mehavioural studies of Apis mellifera . J. Apicul. Res. 52 (4), 1-58

Seeley, T D. (1995) The Wisdom of the Hive. Harvard University Press, Cambridge, MA, USA

SIAP-SAGARPA (2016) Abejas: población apícola 20062015, Colmenas [Online] https://www.gob. $\mathrm{mx} / \mathrm{cms} /$ uploads/attachment/file/165992/abeja.pdf (accessed on 19 October 17)

Teixeira, E.W., dos Santos, L.G., Sattler, A., Message, D., Alves, F.M.T.L.M., Martins, F.M., Grassi-Sella, M.L., Francoy, T.M. (2013) Nosema ceranae has been present in Brazil for more than three decades infecting Africanized honey bees. J. Invert. Pathol. 114, 250254

Therneau, T.M., Grambsch, P.M., Pankratz, V.S. (2003). Penalized survival models and frailty. J. Comput. Graph. Stat. 12, 156-175

Therneau, T.M., Lumley, T. (2015). Package "survival". R. Top. Doc., 128

Vandame, R., Palacio, M.A. (2010) Preserved honey bee health in Latin America: a fragile equilibrium due to low-intensity agriculture and beekeeping? Apidologie $41,243-255$

Williams, G.R., Shutler, D., Little, C.M., BurgherMacLellan, K.L., Rogers, R.E.L., (2011) The microsporidian Nosema ceranae, the antibiotic Fumagilin-B ${ }^{\circledR}$, and western honey bee (Apis mellifera ) colony strength. Apidologie 42 (1), 15-22

Wolf, S., McMahon D.P., Lim, K.S., Pull, C.D., Clark, S.J., Paxton, R.J., Osborne, J.L. (2014) So near and yeat so far: Harmonic radar reveals reduced homing ability of Nosema infected honeybees. PLoS One 9 (8), e103989

Woyciechowski, M., Moron, D. (2009) Life expectancy and onset of foraging in the honeybee (Apis mellifera). Insectes Soc. 56, 193-201 